\title{
Asymmetric Risk Spillover Networks and Risk Contagion Driver in Chinese Financial Markets: The Perspective of Economic Policy Uncertainty
}

\author{
Zongxin Zhang, ${ }^{1}$ Ying Chen $\mathbb{D}^{2}{ }^{2}$ and Weijie Hou ${ }^{3}$ \\ ${ }^{1}$ Institute of Finance, Fudan University, Shanghai 200433, China \\ ${ }^{2}$ School of Economics, Fudan University, Shanghai 200433, China \\ ${ }^{3}$ Antai College of Economics and Management, Shanghai Jiao Tong University, Shanghai 200030, China \\ Correspondence should be addressed to Ying Chen; chenying18@fudan.edu.cn
}

Received 9 May 2021; Accepted 3 September 2021; Published 14 September 2021

Academic Editor: Ning Cai

Copyright (c) 2021 Zongxin Zhang et al. This is an open access article distributed under the Creative Commons Attribution License, which permits unrestricted use, distribution, and reproduction in any medium, provided the original work is properly cited.

\begin{abstract}
The global financial market shocks have intensified due to the COVID-19 epidemic and other impacts, and the impacts of economic policy uncertainty on the financial system cannot be ignored. In this paper, we construct asymmetric risk spillover networks of Chinese financial markets based on five sectors: bank, securities, insurance, diversified finance, and real estate. We investigate the complexity of the risk spillover effect of Chinese financial markets and the impact of economic policy uncertainty on the level of network contagion of financial risk. The study yields three findings. First, the cross-sectoral risk spillover effects of Chinese financial markets are asymmetric in intensity. The bank sector is systemically important in the risk spillover network. Second, the level of risk stress in the real estate sector has increased in recent years, and it plays an important role in the path of financial risk contagion. Third, Economic policy uncertainty has a significant positive impact on the level of network contagion of financial risk of Chinese financial markets.
\end{abstract}

\section{Introduction}

Corresponding to the three main elements of systemic financial risk: shocks, contagion mechanisms, and the consequences of macroeconomic losses. The generation mechanism of systemic financial risk consists of three main processes: the emergence of systemic financial risk triggers, cross-sectoral risk contagion, and the generation of systemic financial risk. In particular, the cross-sectoral risk contagion is the core process of the outbreak of the financial crisis. At present, the global economic and political situation is volatile. The COVID-19 epidemic and the Sino-US trade war have intensified economic policy uncertainty, financial market shocks, and cross-market risk spillover have subsequently increased. It is of great academic value and practical significance to quantify the level of financial market risk spillover, clarify the role of different submarkets in the financial risk spillover network, and explore the driving impact of economic policy uncertainty on financial risk contagion and financial stability.

The paths of systemic financial risk generation and contagion are increasingly complex, with dynamic evolution, nonlinear and networked characteristics. Complex network technology can incorporate financial market complexity into spatial network models and provide a parsing framework for systemic financial risk networked generation mechanisms through network topology analysis, which is an important tool for risk derivation and contagion analysis in financial markets (Caccioli et al. [1]). Traditional risk network models tend to construct risk spillover networks among banks based on asset-liability linkages. While these models are able to capture risk linkages among banks, they neglect cross-sectoral risk spillover arising from indirect linkages and information channel linkages. For 
example, financial risk contagion triggered by the monsoon effect (risk contagion triggered by shocks in macrofundamentals) and pure infection effect (extreme risk contagion) is still in the risk controlling gap. Furthermore, the frequency of balance sheet data is low, and the risk spillover networks constructed from them are often measured after the risk spillover effects have occurred. In addition, Anand et al. [2] point out that stock price is a market representation of a firm's operating conditions and it is more scientific to build a risk spillover network based on the return series of stock price.

Based on the above analysis, this paper constructs asymmetric risk spillover networks of the Chinese financial market using stock market return series of five sectors: banking, securities, insurance, diversified finance, and real estate, and explores the driving impact of economic policy uncertainty on the level of network contagion of financial risk. The main content of this paper consists of three parts as follows. First, constructing cross-sectoral risk spillover networks of Chinese financial markets and second, analyzing the risk spillover characteristics of the Chinese financial market and quantifying the level of network contagion of financial risk, finally, exploring the driving role of economic policy uncertainty on the level of financial risk network contagion through empirical analysis.

The main innovations and contributions of this paper are threefold. First, we construct an asymmetric crosssectoral risk spillover network to analyze the risk linkage and contagion effects among various sectors within the Chinese financial markets. Second, the existing studies on risk contagion mostly focus on the risk association between two pairs. This paper implements an effective measurement of the overall risk contagion level of Chinese financial markets. Third, this paper explores the driving role of economic policy uncertainty on the overall risk contagion level of financial markets, further enriching the researches about economic policy uncertainty and financial stability, which provide references for financial risk prevention and control.

The rest of this paper is organized as follows. Part 2 is the literature review and Part 3 is the model construction. Part 4 reports and discusses the main empirical results in terms of the risk spillover networks and the driving impact of economic policy uncertainty on the level of network contagion of financial risk. Part 5 concludes the study and puts forward the policy implications.

\section{Literature Review}

2.1. Network Contagion of Financial Risk. The network contagion of financial risk refers to the characteristics of the association in the process of systemic financial risk generation due to the cross-contagion of risks within the financial system, i.e., between financial markets and financial institutions (Acemoglu et al. [3]). Complex network modeling is one of the important methods for studying the contagion effects of financial risk networks. The construction of risk networks in financial markets has led to a deeper study of risk contagion. Silva et al. [4] found that the network structure can attenuate or amplify shocks from the real sector by simulating shocks to the real sector and plays an important role in the risk contagion process.

The core of financial risk spillover network construction is the identification of risk spillover intensity and risk spillover direction. Hong et al. [5] study the risk Granger causality to the network system, and Billio et al. [6] extend their study by proposing a systemic financial risk measure based on principal component analysis and Granger causality network. Billio et al. [6] solve the network causal direction identification, then Diebold and Yilmaz [7] propose weighted directed networks based on the variance decomposition method for studying systemic risk spillover. Paltalidis et al. [8] use the maximum entropy method to construct dynamic financial networks, through which they study systemic financial risk and the contagion of crises within the euro area banking system. They confirm the vulnerability of the European banking system by simulating the shocks of systemic financial risk sources through counterfactuals. Regarding the formation of complex risk networks of financial markets, Berndsen et al. [9] propose an interdependent network that couples multiple layers of transmission paths of financial institutions to facilitate a more accurate understanding of the true connectivity architecture of the financial system. Anderson et al. [10] show that transactional behaviors among financial institutions lead financial markets to form a complex network, and the degree of network centrality has an inconsistent effect on the stability of financial markets. They suggest that small and medium-sized financial institutions with a more centralized network structure have better risk diversification, while central banks are exposed to larger shocks that increase network vulnerability.

The network contagion of financial risks is an important link of the outbreak of the financial crisis, Elliott et al. [11] investigate the failure cascade in interdependent financial organization networks, i.e., how discontinuous changes in asset values trigger further failures and their relationship with the structure of financial organization networks. Acemoglu et al. [3] further suggest that the degree of financial contagion manifests itself as a phase transition, where the propagation mechanism of mutual shocks in financial networks leads to a more vulnerable financial system. How to construct cross-sectoral risk spillover networks of financial markets, analyzing the characteristics of risk contagion within financial markets, and quantify the level of the network contagion of financial risk are important to improve the efficiency of financial risk monitoring and control.

2.2. Economic Policy Uncertainty and Financial Risk Contagion. As a significant factor influencing macrofundamental trends, the role of economic policy uncertainty in the cross-market contagion of risk cannot be ignored (Baker et al. [12]). The impact of economic policy uncertainty on the degree of risk contagion of financial markets is often accompanied by unusual volatility in financial markets, which can affect the stock price by influencing inflation, 
interest rates, and expected risk premiums (Pástor and Veronesi $[13,14])$. Dakhlaoui and Aloui [15] find that there is strong evidence of a time-varying correlation between US economic uncertainty and BRIC stock market volatility, and the correlation is highly volatile during periods of global economic instability. Hoque and Zaidi [16] suggest that global economic policy uncertainty can be a systemic risk factor and predictor of stock market returns.

In addition, increased economic policy uncertainty can also exacerbate financial market risk contagion. Dicks and Fulghieri [17] propose that uncertainty is a driver of new systemic risk contagion. Increasing uncertainty makes the financial system more fragile and more prone to crises. Yang et al. [18] use a nonlinear correlation network to study crosscountry systemic financial risk and find that the stock market is the main risk exporter, and the foreign exchange market is the main risk inputter. Their study proves that the economic policy uncertainty plays an important mediating role in both cross-country and cross-market contagion of systemic financial risk. Sharif et al. [19] find that COVID-19 is expected to have a long-term negative effect on the geopolitical risk levels and economic uncertainty. And Li et al. [20] propose that the interaction between EPU in the US and stock returns in China and India is weak in the short term but gradually becomes stronger in the long term, especially when significant financial events occur. The impact of economic policy uncertainty on the level of systemic financial risk contagion has further increased due to the COVID-19 epidemic and the Sino-US trade friction. Li et al. [21] suggest that the correlations between the EPU and financial networks increased significantly during the COVID19 period.

The study of risk contagion should not be limited to the level of risk of individual systemically important financial institutions. Systemic risk contagion is also crucial (Minoiu et al. [22]). However, existing researches are mostly focused on the impact of economic policy uncertainty on abnormal financial market volatility. There are still research gaps with respect to the role of economic policy uncertainty in driving the level of contagion in financial risk networks, which is important for maintaining financial stability and is an important task for global risk management.

\section{Research Design and Methods}

3.1. Sample Selection and Data Acquisition. Data from financial markets are characterized by high frequency, timeliness, and availability (Diebold and Yilmaz [7]; Benoit et al. [23]; Li et al. [21]; Yang et al. [18]). The study of comovements and risk spillover effects within Chinese financial markets based on data from financial markets can provide a global measure of financial risk contagion. Moreover, the construction of the proxy variables for each sector of Chinese financial markets according to the industry classification criteria has become a common approach to study cross-sector risk spillover (Yang et al. [18]; Li et al. [21]; Gong and Xiong [24]).

In this paper, the stock market sector indices of banking, securities, insurance, and diversified finance are selected as proxy variables for each sector of the Chinese financial markets according to the industry classification criteria of Shenyin Wanguo. In addition, considering the increasing risk contagion effect between the real estate sector and the traditional financial sector in the Chinese financial market (Yang et al. [18]; Bai et al. [25]), we add the real estate sector to the financial risk spillover network to study cross-sectoral risk contagion effects. Since the sector indices are nonstationary time series, thus we calculate the daily log returns of each sector index first. The sample period covers from March 2, 2007, to March 5, 2021, and the descriptive statistics of the daily log returns of each index are shown in Table 1.

According to Table 1, the static correlation coefficients among banking, securities, insurance, real estate, and diversified finance are high. The correlation coefficient between the bank sector and the insurance sector is the highest at approximately 0.81 , the correlation coefficients between the securities sector and the other four sectors are greater than 0.7, and the correlation coefficient between the diversified finance and insurance sector is the lowest at approximately 0.642 .

3.2. Model Construction. This paper uses generalized variance decomposition to construct asymmetric risk spillover networks including five sectors: bank, securities, insurance, diversified finance, and real estate (Diebold and Yilmaz [7]; Diebold and Yilmaz [26]), to measure network contagion of financial risk due to direct linkages, indirect linkages, and information channel linkages. As for the stationary multivariate time series $X_{t}$, the VAR (p) model is constructed with an autoregressive process as equation (1), the autoregressive process is transformed into the form of the lag operator as equation (2), and then it is transformed into a moving average process as equation (3).

$$
\begin{aligned}
& X_{t}=\sum_{i=1}^{p} \varphi_{i} X_{t-i}+\varepsilon_{t}, \\
& X_{t}=\Theta(L) \varepsilon_{t}, \\
& X_{t}=\sum_{i=0}^{\infty} A_{i} \varepsilon_{t-i},
\end{aligned}
$$

where $\varepsilon \sim N(0, \Sigma), A_{i}$ is a coefficient matrix of order $N \times N$, obeying the recursive process shown in equation (4), where $A_{0}$ is a unitary array of order $N, i \geq 0$.

$$
A_{i}=\varphi_{1} A_{i-1}+\varphi_{2} A_{i-2}+\cdots+\varphi_{p} A_{i-p} .
$$

The key to constructing a risk spillover network based on the generalized variance decomposition is the calculation of the variance contribution, i.e., the proportion of the $H$-step forecast error of $x_{i}$ that is explained by $x_{j}$ when the variable $x_{i}$ is subject to an external shock: $d_{\mathrm{ij}}(H)$, it is also known as the forecast error variance ratio. The essence of the variance contribution variance ratio $d_{\mathrm{ij}}(H)$ is the extent to which the variable $x_{i}$ is affected by itself and other variables in the system when faced with a market shock, i.e., the distribution 
TABLE 1: Descriptive statistics of variables.

\begin{tabular}{lccccc}
\hline & Bank & Securities & Insurance & Estate & Diversified finance \\
\hline Mean & 0.0098 & 0.0048 & -0.0003 & 0.0089 & 0.0105 \\
Median & -0.0172 & -0.0188 & 0.0183 & 0.0228 & -0.0090 \\
Maximum & 4.1478 & 4.1394 & 4.1469 & 4.0845 & 4.1455 \\
Minimum & -4.5626 & -4.5761 & -4.5764 & -4.2359 & -4.5758 \\
Std. dev. & 0.7969 & 1.1528 & 1.0248 & 0.9198 & 0.9884 \\
Skewness & 0.0194 & -0.0378 & -0.5070 & -0.4888 & -0.0063 \\
Kurtosis & 7.8855 & 5.6911 & 6.1296 & 5.7515 & \\
\hline Static correlation matrix & & & & 0.6845 & \\
\hline Bank & 1.0000 & 0.7160 & 0.8101 & 0.7503 & 0.6542 \\
Securities & 0.7160 & 1.0000 & 0.7530 & 0.6699 & 0.7997 \\
Insurance & 0.8101 & 0.7530 & 1.0000 & 0.0000 & 0.6454 \\
Estate & 0.6845 & 0.7503 & 0.6699 & 0.7555 & \\
Diversified finance & 0.6420 & 0.7997 & 0.6454 & & 0.0000 \\
\hline
\end{tabular}

of incremental risk across sectors of the financial system between its own risk derivation and cross-sectoral risk contagion effects. $d_{\mathrm{ij}}(H)$ is calculated as shown in the following equation:

$$
d_{i j}(H)=\frac{\sigma_{j j}^{-1} \sum_{h=0}^{H-1}\left(e_{i}^{\prime} A_{i} \Sigma e_{j}\right)^{2}}{\sum_{h=0}^{H-1}\left(e_{i}^{\prime} A_{i} \Sigma A_{i}^{\prime} e_{i}\right)^{2}}, i, j=1,2 \ldots N, i \neq j,
$$

where $\Sigma$ is the variance covariance matrix of $\varepsilon_{t}$ and $\sigma_{\mathrm{jj}}$ is the standard deviation of $\varepsilon_{t}$. The $i$-th element of $e_{i}$ is 1 and the remaining elements are $0 . H$ denotes the prediction period and $h$ is the lag order of the perturbation term $\varepsilon_{t}$. Equation (6) is a variance decomposition matrix of order $N \times N$, consisting of the prediction error variance ratio $d_{\mathrm{ij}}(H)$.

$$
D_{i j}(H)=\left(\begin{array}{cccc}
d_{11} & d_{12} & \ldots & d_{1 N} \\
d_{21} & d_{22} & \ldots & d_{2 N} \\
\vdots & \vdots & \ddots & \vdots \\
d_{N 1} & d_{N 2} & \ldots & d_{N N}
\end{array}\right)
$$

The standardized risk spillover matrix $S_{\mathrm{ij}}(H)$ can be obtained using the elements of each row of $D_{\mathrm{ij}(H)}$ divided by the sum of the elements of the row in which they are located, respectively. Assume the corresponding element of $S_{\mathrm{ij}}$ is $z d_{\mathrm{ij}}$, as shown in the following equation:

$$
S_{i j}(H)=\left(\begin{array}{cccc}
z d_{11} & z d_{12} & \ldots & z d_{1 N} \\
z d_{21} & z d_{22} & \ldots & z d_{2 N} \\
\vdots & \vdots & \ddots & \vdots \\
z d_{N 1} & z d_{N 2} & \ldots & z d_{N N}
\end{array}\right) .
$$

In this paper, we use five sectors: bank, securities, insurance, diversified finance, and real estate as the nodes of the risk spillover network, and the standardized risk spillover matrix $S_{\mathrm{ij}}(H)$ between different dimensions as the network weights to construct directed and weighted crosssector risk spillover networks.
The overall connectivity indicator of risk spillover network can denote the level of network contagion of financial risk. In this paper, we use the total risk network connectivity index to measure the level of network contagion of financial risk (Cindex), which is calculated as shown in the following equation:

$$
\text { Cindex }=\frac{1}{N} \sum_{\substack{i, j=1 \\ i \neq j}}^{N} d_{i j}^{H}
$$

This paper constructs an empirical model using the total risk network connectivity index as the explanatory variable and the Chinese economic policy uncertainty index (CEPU) as the core explanatory variable while controlling for the relevant macroeconomic variables: inflation rate (CPI), CSI 300 index turnover rate (HSTR), CSI 300 index price-toearnings ratio (HSPE), industrial value added (IAV), and Treasury term spread (BSPREAD), for investigating the driving impact of economic policy uncertainty on the network contagion level of risk. The regression model is constructed as shown in equation (9), where $X_{t}$ is a vector consisting of control variables and $\beta_{1}$ is the corresponding vector of coefficients to be estimated.

$$
\text { Cindex }{ }_{\mathrm{t}}=\alpha_{0}+\alpha_{1} * C E P U_{t}+\beta_{1} * X_{t} .
$$

\section{Empirical Analysis}

4.1. Risk Spillover Networks Based on Different Financial Sectors. The VAR model is constructed based on five sectors: bank, securities, insurance, diversified finance, and real estate. From Table 1, we can see that the daily log returns of these five sectors are stationary time series, and Table 2 shows the lagged order test of the VAR model.

Combining the lag order test and the parameter significance test of the VAR model with lag order 2, we choose to construct the VAR model with lag order 2 , as in 
TABLE 2: Test of lagged order of VAR model.

\begin{tabular}{|c|c|c|c|c|c|c|}
\hline Lag & $\log L$ & LR & FPE & AIC & SC & HQ \\
\hline 0 & -17614.6 & NA & 0.021 & 10.349 & $10.358^{*}$ & 10.352 \\
\hline 1 & -17529.9 & 169.264 & 0.021 & 10.314 & 10.368 & $10.333^{*}$ \\
\hline 2 & -17496.7 & 66.096 & $0.021^{*}$ & $10.309^{*}$ & 10.408 & 10.345 \\
\hline 3 & -17474.5 & 44.282 & 0.021 & 10.311 & 10.455 & 10.362 \\
\hline 4 & -17452.7 & 43.214 & 0.021 & 10.313 & 10.502 & 10.380 \\
\hline \multicolumn{7}{|c|}{ Joint significance test of VAR (2) parameters } \\
\hline & Bank & Securities & Insurance & Estate & Diversified finance & General \\
\hline Lag 1 & $\begin{array}{l}30.216 \\
{[0.000]}\end{array}$ & $\begin{array}{l}13.304 \\
{[0.021]}\end{array}$ & $\begin{array}{c}23.982 \\
{[0.000]}\end{array}$ & $\begin{array}{l}18.077 \\
{[0.003]}\end{array}$ & $\begin{array}{l}22.359 \\
{[0.000]}\end{array}$ & $\begin{array}{l}166.458 \\
{[0.000]}\end{array}$ \\
\hline Lag 2 & $\begin{array}{c}3.421 \\
{[0.635]}\end{array}$ & $\begin{array}{l}12.296 \\
{[0.031]}\end{array}$ & $\begin{array}{c}2.909 \\
{[0.714]}\end{array}$ & $\begin{array}{c}4.840 \\
{[0.436]}\end{array}$ & $\begin{array}{l}16.368 \\
{[0.006]}\end{array}$ & $\begin{array}{l}68.247 \\
{[0.000]}\end{array}$ \\
\hline
\end{tabular}

${ }^{*} p<0.1,{ }^{* *} p<0.05,{ }^{* * *} p<0.01$.

equation (10), and then construct the prediction error variance ratio $d_{\mathrm{ij}}(H)$.

$$
\left(\begin{array}{c}
\text { bank }_{t} \\
\text { security }_{t} \\
\text { insurance }_{t} \\
\text { estate }_{t} \\
\text { mvfinance }_{t}
\end{array}\right)=A_{1}\left(\begin{array}{c}
\text { bank }_{t-1} \\
\text { security }_{t-1} \\
\text { insurance }_{t-1} \\
\text { estate }_{t-1} \\
\text { mvfinance }_{t-1}
\end{array}\right)+A_{2}\left(\begin{array}{c}
\text { bank }_{t-2} \\
\text { security }_{t-2} \\
\text { insurance }_{t-2} \\
\text { estate }_{t-2} \\
\text { mvfinance }_{t-2}
\end{array}\right)+\left(\begin{array}{c}
\varepsilon_{1 \mathrm{t}} \\
\varepsilon_{2 \mathrm{t}} \\
\varepsilon_{3 \mathrm{t}} \\
\varepsilon_{4 \mathrm{t}} \\
\varepsilon_{5 \mathrm{t}}
\end{array}\right) \text {. }
$$

Table 3 shows the estimation results of VAR (2) model, where the first- and second-order lagged returns of the bank and real estate sectors have an overall positive impact on themselves versus each of the other sectors. The insurance sector with first-order lag has an overall positive impact on other sectors, and the insurance sector with second-order lag has an overall negative impact on other sectors. The overall impact of the diversified financial sector on other sectors is negative with a first-order lag, and the overall impact of the diversified financial sector on other sectors is positive with a second-order lag. The impact of the securities sector on the bank sector and the insurance sector with a first-order lag is negative, and the impact of the securities sector returns on the insurance sector with a second-order lag is negative, and the impact of the returns on the other sectors is positive.

We define $H$ as 10 when calculating the proportion of forecast error variance $d_{\mathrm{ij}}(H)$, and Table 4 shows the matrix of risk spillover effects. The element in row $i$ and column $j$ of the matrix corresponds to $d_{\mathrm{ij}}(H)$, the proportion of the $H$ step forecast error of $x_{i}$ that is explained by $x_{j}$, and $d_{\mathrm{ii}}(H)$ denotes the proportion of the forward $H$-step forecast error of the variable $x_{i}$ that is explained by the variable $x_{i}$ itself. In this paper, we define $d_{\mathrm{ij}}(H)$ as the proportion of the risk spilled from sector $j$ to sector $i$ to the total risk of sector $i$. The larger the value of $d_{\mathrm{ij}}(H)$, the greater the impact of sector $i$ on sector $j$, and the larger the $d_{\mathrm{ii}}(H)$, the greater the risk derived by sector $i$ itself than the risk of contagion from other sectors when facing market shocks.

According to Table 4, there is a distinct asymmetry in the intensity of risk spillover effects between different sectors, i.e., $d_{i j}(H) \neq d_{j i}(H)$. In the face of market shocks, the risk of the bank sector is mainly derived from the bank system, with its internal derivative risk accounting for about $64.994 \%$ of the total risk. However, the percentage of risk spillover from the securities, insurance, real estate, and diversified financial sectors to the bank sector is relatively low, at $15.835 \%$, $21.012 \%, 15.862 \%$, and $12.235 \%$ of the total bank sector risk, respectively. The ratio of derivative risk within the securities sector to total risk is about $33.348 \%$, which is smaller than the total cross-sectoral risk spillover effect of the other four sectors (66.652\%). Meanwhile, the ratio of risk spillover from the bank sector, insurance sector, real estate sector, and diversified financial sector to the securities sector was $15.058 \%, 16.343 \%, 16.426 \%$, and $18.825 \%$, respectively. The ratio of derivative risk within the insurance sector to total risk is about $34.988 \%$, which is smaller than the sum of crosssectoral risk spillover effects from the other four sectors. In particular, the ratio of risk spillover from the bank sector to the insurance sector is the largest, with a value of $20.959 \%$. The risk of the real estate sector is mainly generated within itself, accounting for about $34.657 \%$ of the total risk, while the risk spillover from the bank, securities, insurance, and diversified finance sectors to the real estate sector accounts for $15.651 \%, 17.189 \%, 14.193 \%$, and $18.311 \%$, respectively. The share of internal derivative risk of the diversified financial sector is $35.736 \%$, and the risk spillovers to it from the bank, securities, insurance, and real estate sectors are $12.364 \%, 20.310 \%, 12.669 \%$, and $18.921 \%$, respectively. In particular, the securities sector has the largest share of contagion risk to the diversified financial sector at $20.31 \%$. 
TABLE 3: Estimation results of VAR (2).

Coefficient matrix A1

\begin{tabular}{|c|c|c|c|c|c|}
\hline L1.bank & 0.0291 & 0.0288 & 0.0307 & -0.0164 & 0.0528 \\
\hline L1.estate & -0.0369 & 0.0100 & -0.0602 & 0.0251 & -0.0648 \\
\hline L1.insurance & 0.0509 & -0.0007 & 0.0610 & 0.0228 & 0.0311 \\
\hline L1.mvfinance & -0.0645 & -0.0183 & -0.0629 & 0.0306 & -0.0430 \\
\hline L1.securities & -0.0134 & 0.0490 & -0.0065 & 0.0247 & 0.0526 \\
\hline \multicolumn{6}{|c|}{ Coefficient matrix A2 } \\
\hline L2.bank & -0.0030 & 0.0135 & 0.0514 & 0.0837 & 0.1149 \\
\hline L2.estate & 0.0289 & -0.0455 & -0.0347 & -0.0373 & 0.0033 \\
\hline L2.insurance & -0.0293 & -0.0297 & -0.0206 & -0.0685 & -0.0836 \\
\hline L2.mvfinance & -0.0196 & 0.0254 & 0.0079 & 0.0440 & 0.0209 \\
\hline L2.securities & 0.0168 & 0.0231 & -0.0039 & 0.0360 & 0.0087 \\
\hline
\end{tabular}

TABLE 4: Cross-sectoral risk contagion effect matrix (\%).

\begin{tabular}{|c|c|c|c|c|c|c|}
\hline & Bank & Securities & Insurance & Estate & Diversified finance & Risk absorption \\
\hline Bank & 35.056 & 15.835 & 21.012 & 15.862 & 12.235 & 64.944 \\
\hline Securities & 15.058 & 33.348 & 16.343 & 16.426 & 18.825 & 66.652 \\
\hline Insurance & 20.959 & 17.183 & 34.988 & 14.383 & 12.486 & 65.012 \\
\hline Estate & 15.651 & 17.189 & 14.193 & 34.657 & 18.311 & 65.343 \\
\hline Diversified finance & 12.364 & 20.310 & 12.669 & 18.921 & 35.736 & 64.264 \\
\hline Risk spillover & 64.032 & 70.516 & 64.217 & 65.592 & 61.858 & 326.215 \\
\hline Sum & 99.088 & 103.864 & 99.205 & 100.249 & 97.594 & 65.243 \\
\hline
\end{tabular}

Figure 1 shows the cross-sectoral risk spillover networks constructed based on the risk contagion effect matrix. In order to identify the asymmetry of risk spillover networks, this paper constructs the upper triangular network of risk contagion matrix and the lower triangular network of risk contagion matrix, respectively. In Figure 1, (a) shows the upper triangular network of risk spillover, and (b) shows the lower triangular network of risk spillover. The risk absorption effect portrays the risk transfer taken by each sector from other sectors, and the risk sending effect portrays the risk spillover from each sector to other sectors. According to Figure 1, the risk sending and risk absorbing effects of each sector are asymmetric. According to Figure 1, the risk sending and risk absorbing effects of each sector are asymmetric; i.e., the risk network is asymmetric in intensity. And we find that the securities and bank sectors are most vulnerable to risk fluctuations from other sectors (with the largest risk absorption effect), and the risk absorption effect is stronger in the securities sector than in the bank sector. In addition, the securities sector has the largest risk sending effect.

\subsection{Dynamic Movements of Network Contagion of Financial} Risk. Risk linkages and risk contagion within financial markets have a dynamic change pattern. This paper employs the moving window approach to construct a cross-sectoral risk spillover network of financial markets and further investigates the dynamic changes of the level of the network contagion of financial risk. Figure 2 shows the movement of the risk contagion index (Cindex).

In 2008, due to the global financial crisis caused by the "subprime mortgage crisis," the risk contagion effect of Chinese financial markets intensified, and the risk contagion index rose from around $53 \%$ to around $70 \%$. During 2008-2010, the risk contagion effect weakened, and the risk contagion index fell to around 63\%. In early 2011, the crosssectoral risk contagion effect increased for a short period of time due to the shocks from the bond market, the risk contagion index exceeded $70 \%$, but it decreased in the first quarter of 2012. During the "stock market crash" in 2015, the risk contagion effect of Chinese financial markets reached a new peak, with the risk contagion index at about $72 \%$. But it dropped to its lowest level (around 32\%) from March 2, 2007, to March 5, 2021, due to risk management measures taken by the regulatory authorities. Along with the Sino-US trade war, the risk contagion effect of Chinese financial markets started to increase in the first quarter of 2018, at approximately $70 \%$. Adding the impact of COVID-19, the risk contagion index further enlarged and persists at a high level of $70 \%$ for about two years. With the effective prevention and gradual mitigation of the epidemic in China, the risk contagion effect diminishes in the second half of 2020, with the risk contagion index at about $65 \%$.

Overall, the risk contagion index is an important proxy variable for the level of overall risk contagion in the financial market. It portrays the movement of risk contagion accurately and identifies the rising trend of risk contagion effect during the crisis period.

4.3. Driving Impact of Economic Policy Uncertainty on the Level of Risk Contagion. In this paper, we use risk network connectivity index as the explanatory variable, economic policy uncertainty index as the core explanatory variable, and these variables that reflect domestic macroeconomic and financial fundamentals: inflation, CSI 300 index turnover rate, industrial value added, CSI 300 index PE ratio, and 5- 


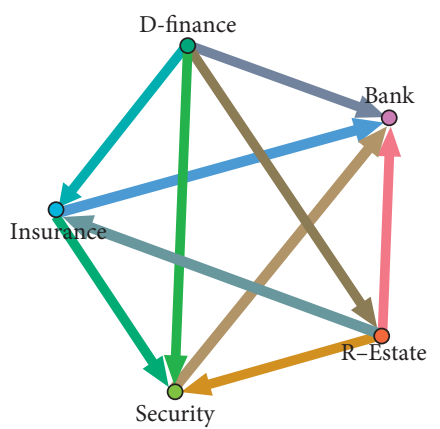

(a)

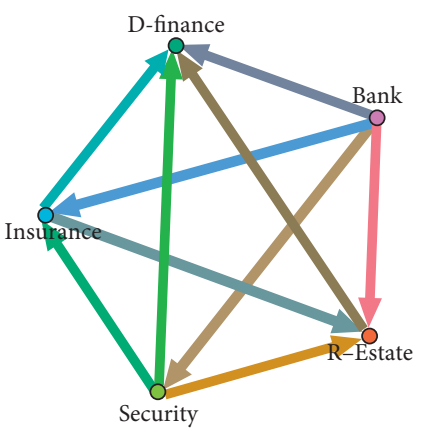

(b)

FIGURE 1: Cross-sectoral risk spillover networks. In the risk spillover networks constructed in this paper, the risk absorption effect mainly refers to how many arrows point to the node, the more arrows pointing to the node, the more cross-sectoral risk contagion sources of the node, the thicker the pointing arrows, the stronger the risk spillover effect. The risk sending effect mainly refers to how many arrows point to other nodes at the node, and the more arrows point from the node, the more sectors are affected by the risk spillover from the node, and the thicker the pointing arrow, the stronger the risk spillover effect. (a) The upper triangular network of risk spillover, (b) The lower triangular network of risk spillover.

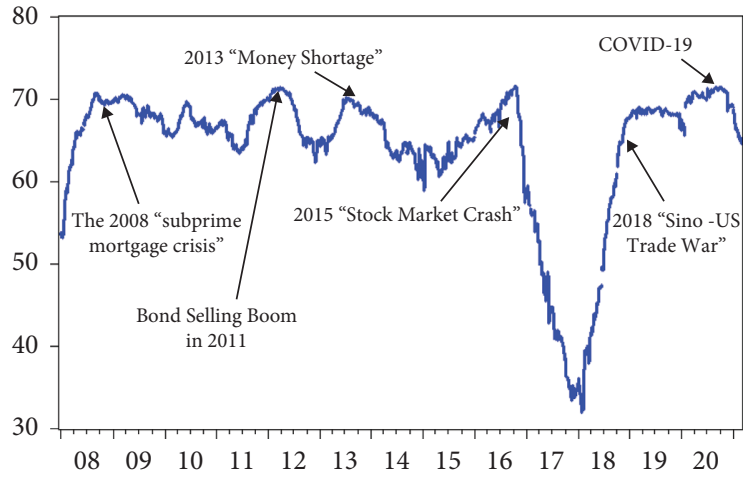

FIgURE 2: Risk contagion index of Chinese financial markets (\%).

year and 6-month treasury term spread as control variables to empirically test the driving impact of economic policy uncertainty on risk contagion in Chinese financial markets. To avoid the pseudoregression that arises from the common trend of variables, we use the HP filtering method to separate the trend terms of all explanatory variables, leaving the periodic terms for model estimation. The periodic terms of the variables separated by HP filtering are all stationary time series, and Table 5 shows the model estimation results.

In Table 5, models (1), (2), and (3) all use risk contagion index as the explanatory variables, the explanatory variable in model (1) is the Chinese economic policy uncertainty index, the explanatory variables in model (2) are control variables such as inflation rate, and model (3) adds control variables based on model (1). From Table 5, we can know that the economic policy uncertainty index has a significant positive effect on the risk contagion index of Chinese financial markets. That is, the higher the economic policy uncertainty, the higher the level of risk contagion. After adding macroeconomic and financial variables, the effect of economic policy uncertainty on the level of risk contagion is still significantly positive.
4.4. Robustness Test. This paper selects 19 financial institutions belonging to the banking, securities, and insurance sectors and 5 firms belonging to the real estate sector to construct interinstitutional asymmetric risk spillover networks and risk contagion index for testing the robustness of the driving impact of economic policy uncertainty on the level of risk contagion. Considering the availability of data, the 19 financial institutions include 7 banks, 3 insurance companies, and 9 securities companies. Since the number of listed companies of the real estate sector is large and the time span is long, we select five real estate companies with the largest market capitalization. The names of selected institutions in each sector are shown in Table 6, and each financial institution is used as the central node to construct an interinstitutional asymmetric risk spillover network.

Figure 3 shows the risk spillover networks diagram constructed based on the risk spillover matrix between 19 financial institutions and 5 real estate companies. In Figure 3, (a) shows the network of upper triangular, (b) shows the network of lower triangular. According to Figure 3, we can see that the risk spillover effect of bank sector firms to firms belong to securities, real estate, and insurance sectors is 
TABLE 5: Estimation results of regression.

\begin{tabular}{lccc}
\hline & $(1)$ & $(2)$ & $(3)$ \\
\hline CEPU & & & $0.0058^{* *}$ \\
CPI & & -1.2281 & 0.3378 \\
CSI 300 turnover rate & $0.0058^{* *}$ & -0.1038 & -0.8497 \\
Industrial value added & & $-0.6000^{* * *}$ & -0.1130 \\
CSI 300 PE ratio & & $5.5265^{* *}$ & $-0.5929^{* * *}$ \\
Treasury term spread & $3.36 E-12$ & $2.94 E-12$ & $5.6745^{* *}$ \\
C & 0.0250 & 0.1869 & $2.8 E-12$ \\
\hline$R$-squared & 0.0188 & 0.1601 & 0.2112 \\
Adjusted $R^{2}$ & & & 0.1799 \\
\hline
\end{tabular}

${ }^{*} p<0.1,{ }^{* *} p<0.05,{ }^{* * *} p<0.01$.

TABLE 6: Selection of the nodes of institutional risk spillover network.

\begin{tabular}{lrc}
\hline Department & Name of institution & Node number \\
\hline $\begin{array}{l}\text { Bank } \\
\text { Estate }\end{array}$ & $\begin{array}{r}\text { Ping An Bank, Shanghai Pudong Development Bank, Huaxia bank, China Minsheng Bank, China } \\
\text { Merchant's Bank, Industrial and Commercial Bank of China }\end{array}$ & node1-node7 \\
Insurance & Vanke, Shenzhen Zhenye, Shenzhen Property, Shahe industry, Grandjoy & node8-node12 \\
& Hubei Biocause Pharmaceutical, Ping An Insurance of China, China Life Insurance & node15 \\
Securities & Northeast Securities, Guangdong Golden Dragon Development, Guangzhou Yuexiu Financial Holdings & node16- \\
& Group, CITIC Securities, SDIC Capital, Xiangcai, China Fortune Securities Investment Company, Haitong & node24 \\
\hline
\end{tabular}

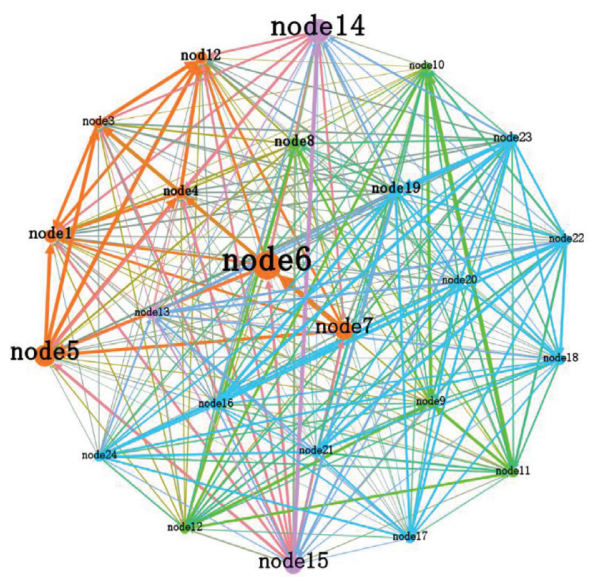

(a)

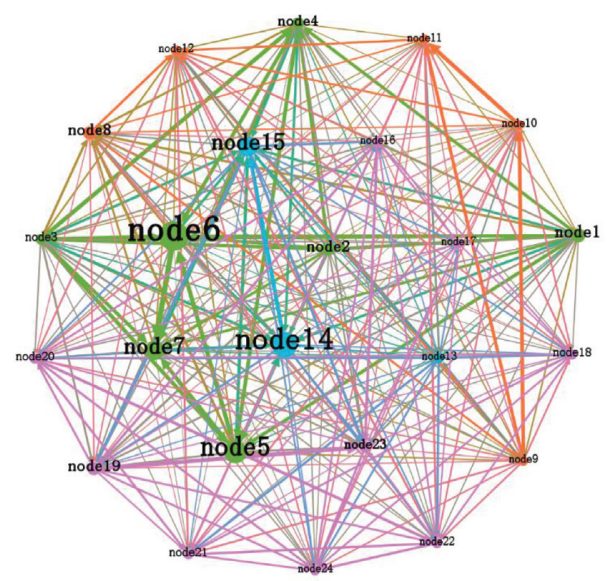

(b)

FIGURE 3: Interinstitutional risk spillover networks (average). Consistent with the risk spillover networks constructed for each sector of Chinese financial markets, the return series of 19 financial institutions, and 5 real estate companies are all stationary time series. Based on the lag order test, we construct a second-order VAR model and calculate the proportion of variation in forecast error $d_{i j}(10)$ for the forward 10step forecast. In a single risk spillover network, network nodes and connected edges are identified using the same color for institutions belonging to the same sector. The node size of the interinstitutional risk spillover network corresponds to the market capitalization of the institution. The larger the market capitalization, the larger the network node, and the thickness of the contiguous edges of the network nodes indicates the strength of the risk contagion level. The thicker the contiguous edges of the network, the stronger the risk contagion effect. (a) The upper triangular network of risk spillover. (b) The lower triangular network of risk spillover.

large, while companies in the securities, real estate, and insurance sectors have relatively small risk spillover effects on companies in the banking sector. Risk spillover networks are typically asymmetric.

Table 7 presents the estimation results of the robustness test of the risk contagion index constructed based on the interinstitutional asymmetric risk spillover networks. According to Table 7, the conclusion that the economic policy uncertainty index has a significant positive driving impact on the risk contagion index still holds.

In addition, this paper tests the robustness of the impact of economic policy uncertainty on the level of risk contagion by using the Global Economic Policy Uncertainty (GEPU) Index instead of the Chinese Economic Policy Uncertainty Index. The model estimation results are shown in Table 8 . According to Table 8, this conclusion still holds. 
TABLE 7: Robustness tests based on risk contagion index of 24 firms.

\begin{tabular}{lccc}
\hline & $(1)$ & $(2)$ & $(3)$ \\
\hline CEPU & & & $0.0038^{*}$ \\
CPI & & -0.2678 & -0.2011 \\
CSI 300 turnover rate & $0.0040^{* *}$ & -0.9505 & -0.7003 \\
Industrial value added & & -0.0940 & -0.1001 \\
CSI 300 PE ratio & & $-0.3782^{* * *}$ & $-0.3735^{* * *}$ \\
Treasury term spread & & $5.1000^{* * *}$ & $5.1979^{* * *}$ \\
C & $-8.87 E-12$ & $-9.49 E-12$ & $-9.59 E-12$ \\
\hline$R$-squared & 0.0216 & 0.2067 & 0.2251 \\
Adjusted $R^{2}$ & 0.0153 & 0.1807 & 0.1943 \\
\hline
\end{tabular}

${ }^{*} p<0.1,{ }^{* *} p<0.05,{ }^{* * *} p<0.01$.

TABLE 8: Robustness test based on the global economic policy uncertainty index.

\begin{tabular}{lccc}
\hline & $(1)$ & $(2)$ & $(3)$ \\
\hline GEPU & & & $0.0475^{* * *}$ \\
CPI & & 0.2370 & 0.2517 \\
CSI 300 turnover rate & $0.0604^{* * *}$ & -0.1038 & -0.0550 \\
Industrial value added & & -1.2281 & -0.9464 \\
CSI 300 PE ratio & & $-0.6000^{* * *}$ & $-0.4755^{* * *}$ \\
Treasury term spread & & $5.5265^{* * *}$ & $5.8121^{* * *}$ \\
C & $4.55 E-12$ & $2.94 E-12$ & $3.93 E-12$ \\
\hline$R$-squared & 0.1380 & 0.1869 & 0.2624 \\
Adjusted $R^{2}$ & 0.1325 & 0.1601 & 0.2331 \\
\hline
\end{tabular}

${ }^{*} p<0.1,{ }^{* *} p<0.05,{ }^{* * *} p<0.01$.

\section{Conclusion}

This paper constructs asymmetric risk spillover networks and risk contagion index for Chinese financial markets based on the bank, securities, insurance, diversified finance, and real estate sectors. The driving impact of economic policy uncertainty on the level of risk contagion in financial markets is investigated. This paper draws the following conclusions. First, the risk contagion effect within Chinese financial markets has dynamic change characteristics, and the risk spillover effects among different sectors are asymmetric in intensity. Second, the risk spillover effect of the real estate sector does not diminish with the mitigation of the COVID-19 epidemic, and the current potential risk in the Chinese real estate market is larger. Third, economic policy uncertainty has a significant positive impact on the level of overall risk contagion in Chinese financial markets.

Based on a comprehensive analysis of the level of risk contagion in Chinese financial markets, this paper proposes the following implications. First, economic policy uncertainty is tightly related to risk contagion and shocks of financial markets. Therefore, regulatory authorities should be cautious in dealing with the adverse effects of economic policy uncertainty on financial markets to avoid the spread of negative public emotion due to economic policy uncertainty, which could lead to financial crises. Second, the contagion of financial risks is an asymmetric network that intersects with each other, and the regulatory authorities should distinguish the role of different sectors in risk contagion. Third, the trend of financialization of real estate is increasingly obvious, and regulatory authorities should focus on potential sources of systemic financial risk induced by the real estate sector by actively studying the risk transmission mechanism between the real estate market and the financial markets.

\section{Data Availability}

The data used in this study are available from the corresponding author upon request.

\section{Conflicts of Interest}

The authors declare that there are no conflicts of interest regarding the publication of this paper.

\section{Acknowledgments}

This work was supported by the National Natural Science Foundation of China (7207030651).

\section{References}

[1] F. Caccioli, P. Barucca, and T. Kobayashi, "Network models of financial systemic risk: a review," Journal of Computational Social Science, vol. 1, no. 1, pp. 81-114, 2018.

[2] K. Anand, B. Craig, and G. Von Peter, "Filling in the blanks: network structure and interbank contagion," Quantitative Finance, vol. 15, no. 4, pp. 625-636, 2015.

[3] D. Acemoglu, A. Ozdaglar, and A. Tahbaz-Salehi, "Systemic risk and stability in financial networks," The American Economic Review, vol. 105, no. 2, pp. 564-608, 2015.

[4] T. C. Silva, M. A. Da Silva, and B. M. Tabak, "Bank lending and systemic risk: a financial-real sector network approach with feedback," Journal of Financial Stability, vol. 38, pp. 98-118, 2017.

[5] Y. Hong, Y. Liu, and S. Wang, "Granger causality in risk and detection of extreme risk spillover between financial markets," Journal of Econometrics, vol. 150, no. 2, pp. 271-287, 2009.

[6] M. Billio, M. Getmansky, A. W. Lo, and L. Pelizzon, "Econometric measures of connectedness and systemic risk in the finance and insurance sectors," Journal of Financial Economics, vol. 104, no. 3, pp. 535-559, 2012.

[7] F. X. Diebold and K. YiLmaz, "Measuring financial asset return and volatility spillovers, with application to global equity markets," The Economic Journal, vol. 119, no. 534, pp. 158-171, 2009.

[8] N. Paltalidis, D. Gounopoulos, R. Kizys, and Y. Koutelidakis, "Transmission channels of systemic risk and contagion in the European financial network," Journal of Banking \& Finance, vol. 61, pp. 36-52, 2015.

[9] R. J. Berndsen, C. León, and L. Renneboog, "Financial stability in networks of financial institutions and market infrastructures," Journal of Financial Stability, vol. 35, pp. 120-135, 2016.

[10] H. Anderson, M. Paddrik, and J. J. Wang, "Bank networks and systemic risk: evidence from the national banking acts," The American Economic Review, vol. 109, no. 9, pp. 3125-3161, 2019.

[11] M. Elliott, B. Golub, and M. O. Jackson, "Financial networks and contagion," The American Economic Review, vol. 104, no. 10, pp. 3115-3153, 2014. 
[12] S. R. Baker, N. Bloom, and S. J. Davis, "Measuring economic policy uncertainty*," Quarterly Journal of Economics, vol. 131, no. 4, pp. 1593-1636, 2016.

[13] L. Pástor and P. Veronesi, "Uncertainty about government policy and stock prices," The Journal of Finance, vol. 67, no. 4, pp. 1219-1264, 2012.

[14] Ľ. Pástor and P. Veronesi, "Political uncertainty and risk premia," Journal of Financial Economics, vol. 110, no. 3, pp. 520-545, 2013.

[15] I. Dakhlaoui and C. Aloui, "The interactive relationship between the US economic policy uncertainty and BRIC stock markets," International Economics, vol. 146, pp. 141-157, 2016.

[16] M. E. Hoque and M. A. S. Zaidi, "The impacts of global economic policy uncertainty on stock market returns in regime switching environment: evidence from sectoral perspectives," International Journal of Finance \& Economics, vol. 24, no. 2, pp. 991-1016, 2019.

[17] D. L. Dicks and P. Fulghieri, "Uncertainty aversion and systemic risk," Journal of Political Economy, vol. 127, no. 3, pp. 1118-1155, 2019.

[18] Z. H. Yang, R. X. Chen, and Y. T. Chen, "Economic policy uncertainty and cross-market contagion of systemic financial risk: a study based on nonlinear network correlation," Economic Research, vol. 55, no. 1, pp. 65-81, 2020.

[19] A. Sharif, C. Aloui, and L. Yarovaya, "COVID-19 pandemic, oil prices, stock market, geopolitical risk and policy uncertainty nexus in the US economy: fresh evidence from the wavelet-based approach," International Review of Financial Analysis, vol. 70, Article ID 101496, 2020.

[20] R. Li, S. Li, D. Yuan, and K. Yu, "Does economic policy uncertainty in the U.S. influence stock markets in China and India? time-frequency evidence," Applied Economics, vol. 52, no. 39, pp. 4300-4316, 2020.

[21] Y. Li, J. Luo, and Y. Jiang, "Policy uncertainty spillovers and financial risk contagion in the Asia-Pacific network," PacificBasin Finance Journal, vol. 67, Article ID 101554, 2021.

[22] C. Minoiu, C. Kang, V. S. Subrahmanian, and A. Berea, "Does financial connectedness predict crises?" Quantitative Finance, vol. 15, no. 4, pp. 607-624, 2015.

[23] S. Benoit, J.-E. Colliard, C. Hurlin, and C. Pérignon, "Where the risks lie: a survey on systemic risk"," Review of Finance, vol. 21, no. 1, pp. 109-152, 2017.

[24] X. L. Gong, X. Xiong, and W. Zhang, "Research on systemic risk measures and spillover effects of financial institutions in China," Management World, vol. 36, no. 8, pp. 65-83, 2020.

[25] H. X. Bai, S. F. Liu, X. W. Luo, L. L. Liu, and W. Y. Hao, "Research on the measurement and early warning of systemic financial risk in China based on real estate market," Financial Research, vol. 8, pp. 54-73, 2020.

[26] F. X. Diebold and K. Yilmaz, "On the network topology of variance decompositions: measuring the connectedness of financial firms," Journal of Econometrics, vol. 182, no. 1, pp. 119-134, 2014. 